\title{
Blockchain Technology Opportunities in Kurdistan, Applications and Challenges
}

\author{
Hilmi Abdullah, Ali Hikmat Ibrahim \\ Amedi Technical Institute, Duhok Polytechnic University, Iraq
}

\begin{tabular}{l}
\hline Article Info \\
\hline Article history: \\
Received Aug 23, 2019 \\
Revised Oct 25, 2019 \\
Accepted Nov 18, 2019 \\
\hline
\end{tabular}

\section{Keywords:}

Bitcoin

Blockchain

Cryptography

Decentralization

Distributed Ledger

\begin{abstract}
Recently, the blockchain technology has received a vast popularity because it brought revolutionary changes to some industries due to the fact that this technology enables the implementation of secure, decentralized and trustworthy applications. Moreover, this technology has many advantages over centralized systems such as immutability and transparency. The most common application of the blockchain technology is the Bitcoin cryptocurrency, which provides a method of transferring money in a secure way without the involvement of a central authority. In addition to the Bitcoin, there are other applications based on the blockchain technology in a variety of sectors and industries such as governance, healthcare and supply chain. In this paper, we discuss blockchain applications that can be implemented in Kurdistan and we highlight their opportunities and challenges.
\end{abstract}

Copyright $@ 2020$ Institute of Advanced Engineering and Science. All rights reserved.

\section{Corresponding Author:}

Hilmi Abdullah,

IT Department, Amedi Technical Institute,

Duhok Polytechnic University, Iraq.

Email: hilmi.amedi@gmail.com

\section{INTRODUCTION}

The information technology is advancing rapidly in developing new ways of data transfer in an easier, faster and more secure manner. Until recently, most of the data shared between different parties was stored in a central database which was controlled and facilitated by a central authority. However, there are some concerns associated with the centralized systems; the most important one is that there is a single point of failure as well as trust and transparency issues. The solution to the mentioned concerns is the blockchain technology. This technology eliminates the need of central authority by implementing a distributed database for storing transaction information which is shared and synchronized among the involved parties using a peer-to-peer network [1].

Nowadays, various sectors are exploring the utilization of blockchain technology by developing applications based on this technology to meet security and transparency criteria. The most common application is Bitcoin which is a cryptocurrency that enables transferring digital money without the need of a middle man. Furthermore, many other blockchain based applications are introduced for a variety of sectors such as healthcare, supply chain, governance, etc [2].

However, despite having several advantages, the Kurdistan government hasn't yet embraced this technology to solve some of the problems. One of the problems is related to the financial sector which according to [3] the majority of Kurdistan citizens doesn't use bank services and aren't involved in ecommerce, by using the blockchain and cryptocurrencies this problem can be solved, and it will have a positive impact on the economy. The second problem is related to imported retail products in Kurdistan, which consumers are concerned about their origins, shipping and storage conditions, However, implementing a blockchain based system of supply chain will increase consumer's trust and have a better impact on their health [4-5]. Another problem is that citizens have lost faith in the government elections because of 
transparency issues [6], therefore, implementing a blockchain based e-voting system in Kurdistan will increase voters' participation rate as the votes will be immutable.

In this paper, we focus on three sectors in Kurdistan which may benefit from the blockchain technology by exploring their opportunities and challenges. The rest of the paper is organized as follows. Section 2 provides the basic concepts of the blockchain technology, blockchain types and components. Section 3 discusses the various applications of blockchain and their opportunities and challenges in Kurdistan. Section 4 presents the results and discussions. Finally, conclusion in is provided in section 5.

\section{LITERATURE REVIEW}

\subsection{The Concept of Blockchain}

Blockchain Technology was first outlined by a group of researchers in 1991. Blockchain is defined as a chain of blocks which store transaction information over a network of computers called nodes. All the nodes contain the same transactions history which makes the blockchain a decentralized system as there is no central point of control [7]. In traditional systems, there is a central database which stores the data and is managed by a centralized authentication system [8]. On the other hand, the blockchain is managed by a peerto-peer network and the data is stored in a distributed ledger. The ledger consists of a chain of blocks which are encrypted and linked to each other using hash as in Figure 1 [9]. New blocks are validated and confirmed through consensus on the network and added to the ledger. The consensus mechanism ensures integrity and consistency of the blockchain. Once the blocks are added, they cannot be altered without altering the subsequent blocks, because tampering a block will cause an error in the previous block and so on [7, 10]. For this reason, the blockchain is considered a secure system as it is nearly impossible to tamper its ledger [9].

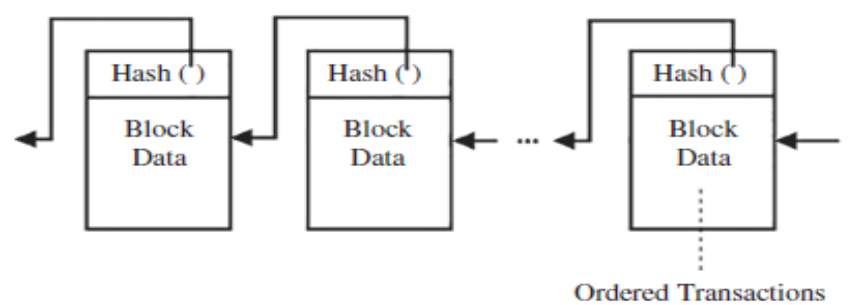

Figure 1. Blockchain Structure

In addition to the decentralization and distributed ledger characteristics, the blockchain technology has several other characteristics which are combined and presented in Figure 2 [11].

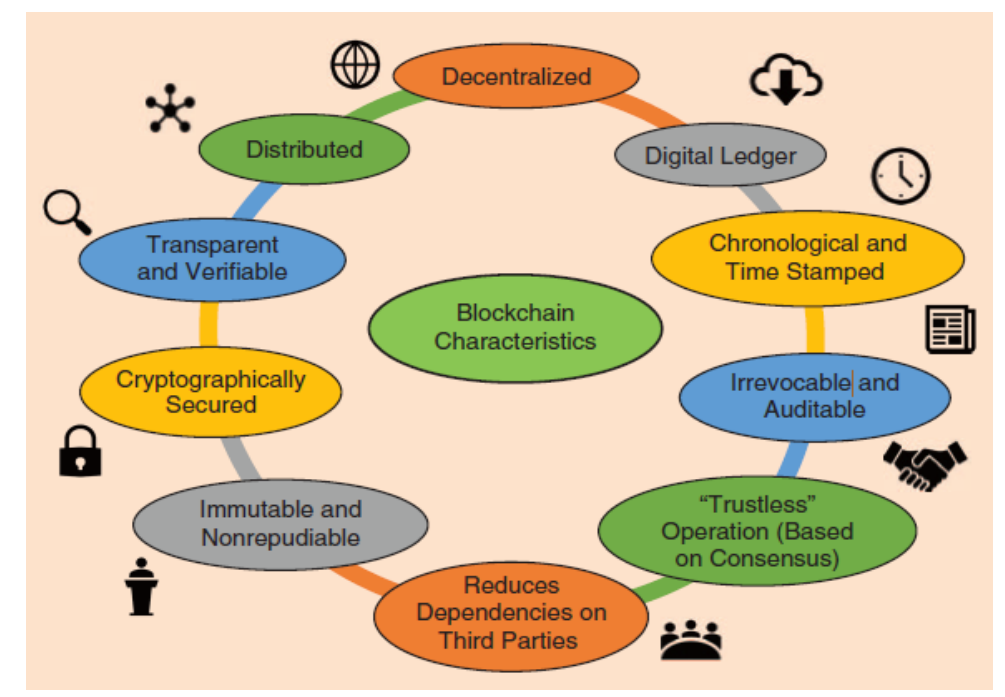

Figure 2. Blockchain Characteristics 


\subsection{Blockchain Components}

In general, the blockchain consists of four core components regardless of the blockchain type and application as shown in Figure 3 [1-2].

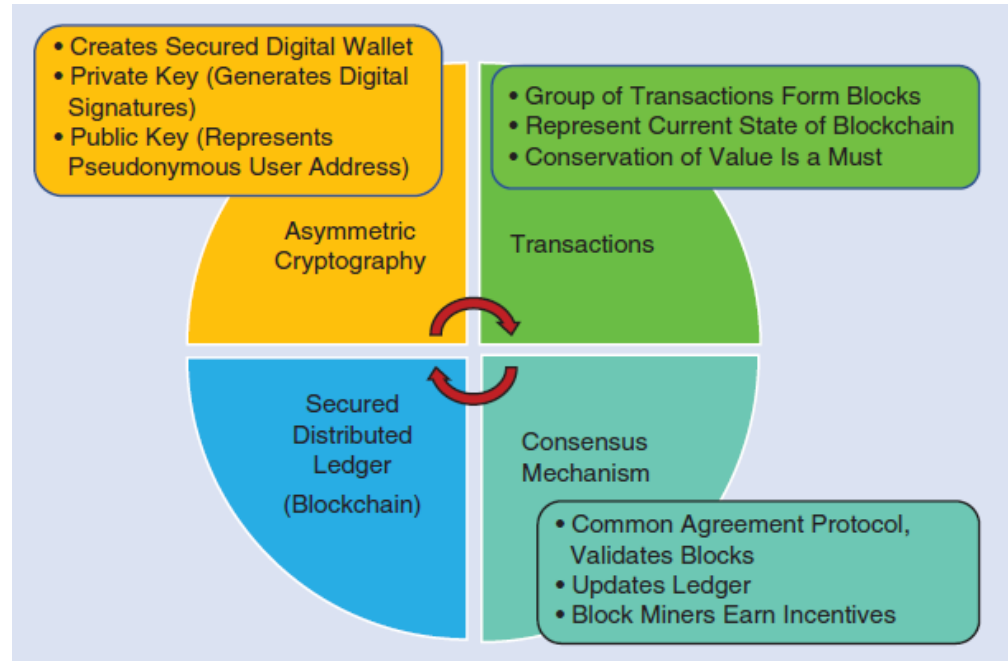

Figure 3. Blockchain Components

\subsubsection{Transactions}

Transactions are the smallest building blocks of the blockchain technology. They can hold data which are transferred between blockchain nodes on a peer-to-peer basis. As a rule, transactions are created by the sender and propagated to the network, later on, blockchain network nodes validate and gather them in blocks which are finally added to the ledger [1-2]. Figure 4 [12] shows the transactions inside the blocks.

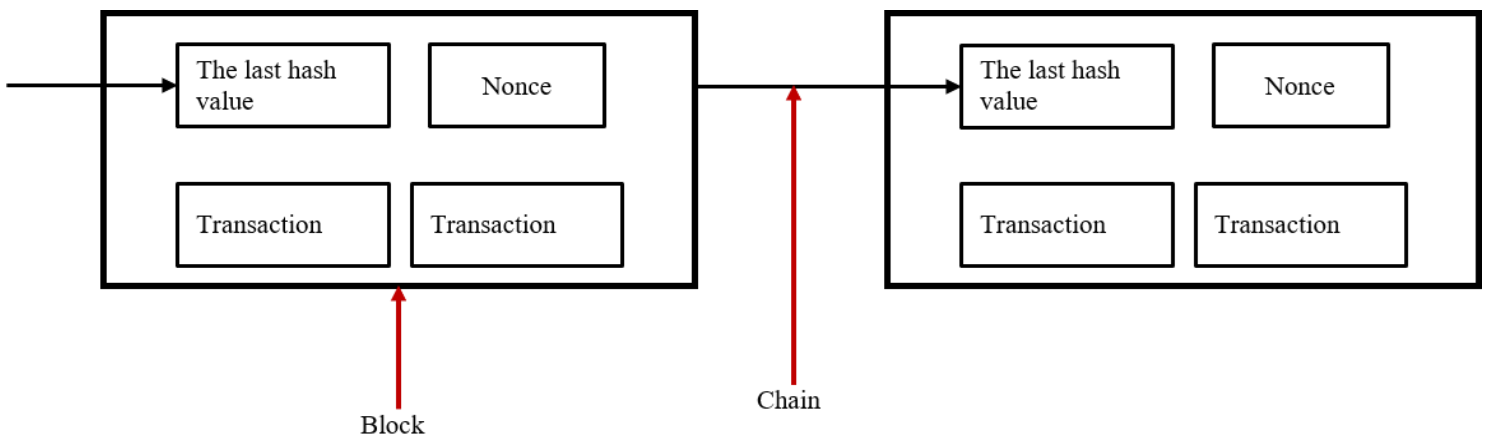

Figure 4. Blockchain Transactions and Blocks

\subsubsection{Ledger}

Ledger is a database which stores the transactions. The ledger is shared, replicated and synchronized among the nodes of the blockchain network. Furthermore, the ledger is updated when the nodes of the blockchain network agree on the updates using consensus mechanism [1-2, 7].

\subsubsection{Consensus Mechanism}

Since there is no central party to take decisions and regulate data sharing between the nodes, therefore a mechanism is needed to make decisions in order to keep track of the transactions and maintain the state and consistency of the blocks. This mechanism is called consensus, where blocks are added to the blockchain only when the majority of the nodes agree. Moreover, using consensus mechanism the blockchain ensures that there is only one single history of the blocks in the ledger [1-2]. 


\subsubsection{Cryptography}

This component is necessary to preserve the privacy and security of the blockchain. It is primarily used for two purposes; first, securing the identity of the sender by using public, private keys and cryptographic digital signatures. Second, ensuring that the previous records of the ledger are immutable by using hash function to encrypt the new block and connect it to previous blocks; therefore, altering any block can't be done without altering subsequent blocks too [1-2, 13].

\subsection{Blockchain Types}

Generally, there are three main types of blockchain, public, private and consortium [1].

\subsubsection{Public Blockchain}

As the name implies it can be accessed by anyone who has internet. Users can perform transactions and audit the blockchain with no restrictions. This type of blockchain is transparent and is not controlled by any organization. An example of this type is the Bitcoin blockchain which is available to all the participants with no restrictions $[1-2,14]$.

\subsubsection{Private Blockchain}

This type of blockchain can be used to share data among the users within the same organization or multiple organizations. Unlike the public blockchain, the private blockchain users are required to gain permission to access the network which is typically done through an invitation to join. An example of the private blockchain would be a file distribution network $[1-2,14]$.

\subsubsection{Consortium Blockchain}

This type of blockchain is partially private and partially public. Unlike public blockchain only specific nodes are permitted to validate the transactions. An example of consortium blockchain would be some of the cryptocurrencies now in use such as Ripple [1-2, 14].

\section{BLOCKCHAIN APPLICATIONS AND CHALLENGES}

Generally speaking, the most popular application of blockchain is the Bitcoin. The Bitcoin is decentralized digital money invented by Satoshi Nakamoto in 2009 based on the blockchain technology. However, there are several other applications and use cases of the blockchain in a variety of sectors. The following describes some of the blockchain applications, and their opportunities and challenges in Kurdistan [2, 7, 15].

\subsection{Financial Applications}

Nowadays, there are a many cryptocurrencies based on blockchain such as Bitcoin, Ethereum and Ripple. The idea of using blockchain in the financial applications is to create digital money that is not controlled by governments and third-party institutions. Bitcoin for instance has no central authority and uses a public distributed ledger to record transactions [16-18].

Traditional currencies are controlled by governments and all transactions are recorded and authorized by centralized third parties like banks [7]. On the other hand, Bitcoin and other cryptocurrencies' transactions and payments can be made directly without the need of centralized third party or middle men; instead it uses mining process to endorse Bitcoin transactions as shown in Figure 5 [15, 19].

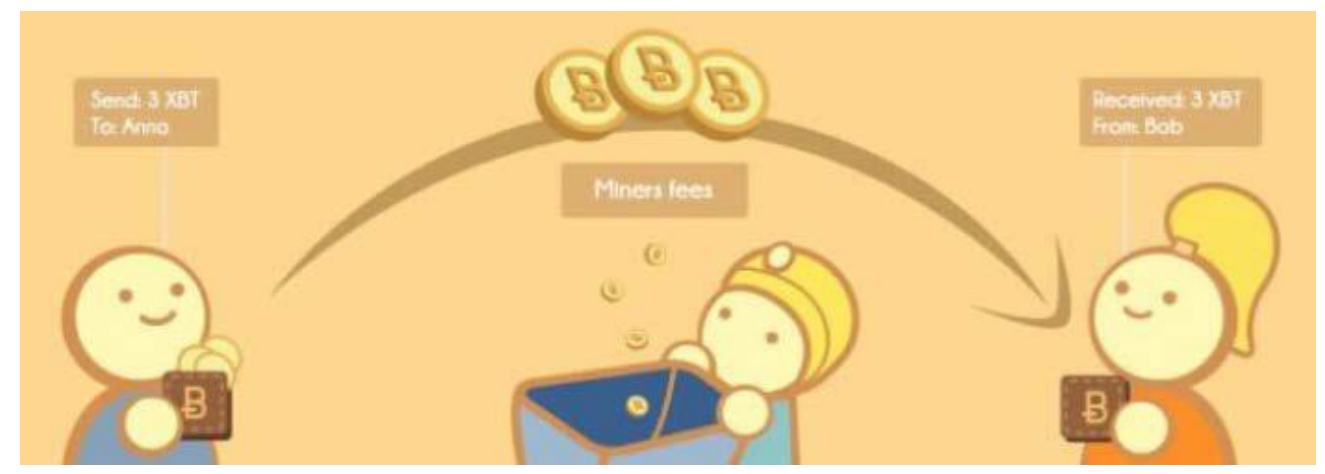

Figure 5. Bitcoin Application 
There are many benefits of using Bitcoin and other cryptocurrencies in financial transactions. One of them is the elimination of unnecessary fees which are paid to the middle men, for instance, international money transfers could be achieved with a lower cost as well as the processing time is faster compared to the traditional currencies [7]. Another advantage is the availability and security of the blockchain network [20].

Moreover, according to [21] there are several countries considering creating their own cryptocurrency such as Russia, Iran and Venezuela. The adoption of blockchain for financial services may have positive effects on the economy in Kurdistan as well, where it is estimated that less than $10 \%$ of its adults have bank accounts. In other words, the vast majority of Kurdistan citizens doesn't use bank services and aren't involved in e-commerce [3]. For this reason, blockchain and cryptocurrencies can be a good solution, as people will simply need access to the internet and a software wallet to perform their financial transactions which will lead to a boost in the economy of Kurdistan. However, there are some challenges facing this potential, firstly, the lack of digital literacy among the citizens, secondly, price fluctuation of cryptocurrencies, thirdly, the need for regulations of cryptocurrencies and finally, security concerns associated with digital money.

\subsection{Governance}

Blockchain has a huge potential in providing government services in a secure and transparent way. Many governments have taken initiatives in implementing the blockchain in various sectors [2]. One of the applications that attracts the governments is E-Voting. Implementing a voting system based on the blockchain technology will make the voting process faster, easier, cheaper, secure and transparent. Since the blockchain records can't be altered easily, the votes will be recorded accurately without any possibility of votes modifications. Moreover, blockchain based E-Voting has already been implemented and tested successfully in several countries around the globe [22-23].

According to [6] there was a low turnout among the voters in the last parliamentary elections in 2018 and there is a continuous decline in turnout since the first elections in 1992. There could be many factors of the low turnout most importantly is transparency concerns. Therefore, implementing a blockchain based e-voting system in Kurdistan may increase voters' participation rate because with such an application, citizens can track their votes and ensure that they are counted for whom they voted for. In addition, this system will save money for the government and make the voting process easier. However, the most important challenge for implementing blockchain based systems for governance might be regulation and political issues.

\subsection{Supply Chain}

Typically, consumers are concerned about the quality and safety of the products they buy such as food and medications. Therefore, it is important to have an application or a method for this purpose to ensure consumers' satisfaction. Currently, there are traditional methods which lack transparency and accuracy. Whereas, Blockchain provides a perfect solution to problems related to the quality and safety of products by tracing them from the source until they reach the consumers. Since the blockchain network is not owned and controlled by a single entity, the data records will be more trustworthy and immutable [4-5]. Moreover, integrating the blockchain with the Internet of things (IoT) devices will further improve the tracking process because the IoT devices can update status and record details without the need of manual intervention [2, 24].

Nowadays, most of the food and retail products in Kurdistan are imported from other countries. Consumers are always concerned about the origins of the products, shipping and storage conditions. Implementing a blockchain based system for the food industry in Kurdistan will help the consumers in tracing the source of the products and their storage conditions before deciding to buy them. In fact, such a system will eliminate the lack of traceability and transparency; hence, it will have a positive effect on consumers' health and satisfaction. However, there are many challenges involved, most importantly; there are many contributors, such as producers, shippers and resellers which all have to agree to participate in order for the system to succeed.

\section{RESULTS AND DISCUSSION}

The study reveals that there is huge potential for the blockchain technology in different sectors in Kurdistan such as financial, governance and supply chain. In the financial sector it will help engage more citizens in the e-commerce. Another sector is the Governance, the blockchain will increase citizens trust. Finally, using the blockchain in supply chain will have a positive impact on consumers health and convenience. However, there are some challenges facing blockchain applications in each sector such as the lack of digital literacy among the citizens, the need for regulations and data security issues. 


\section{CONCLUSION}

Blockchain is a revolutionary technology which enables data transaction using a decentralized structure and a distributed database eliminating the need for a central authority. Hence, various sectors can adopt blockchain and benefit from this technology. However, embracing this technology doesn't come without obstacles and challenges. Future research is needed to come up with novel solutions to overcome the discussed difficulties and challenges in implementing blockchain applications in Kurdistan.

\section{REFERENCES}

[1] D. Puthal, N. Malik, S. P. Mohanty, E. Kougianos and G. Das, "Everything You Wanted to Know About the Blockchain: Its Promise, Components, Processes, and Problems" in IEEE Consumer Electronics Magazine, vol. 7, no. 4, pp. 6-14, July 2018.

[2] A. Alketbi, Q. Nasir and M. A. Talib, "Blockchain for government services-Use cases, security benefits and challenges" 2018 15th Learning and Technology Conference (L\&T), Jeddah, 2018, pp. 112-119.

[3] A. Bartnick, "Obstacles and Opportunities for Entrepreneurship in Iraq and the Kurdistan Region", Institute of Regional and International Studies (IRIS), AUIS, July 2017, Available at https://auis.edu.krd/iris/sites/default/files/IRIS_Entrepreneurship\%20in\%20Iraq\%20and\%20KRI\%20report.pdf Accessed on 7.6.2019.

[4] N. Kshetri and E. Loukoianova, "Blockchain Adoption in Supply Chain Networks in Asia", IT Professional, vol. 21, no. 1, pp. 11-15, 2019.

[5] Ahmad Nurul Fajar, Ditdit Nugeraha Utama, "SGSC Framework: Smart Government in Supply Chain Based on FODA", Bulletin of Electrical Engineering and Informatics (BEEI), Vol. 7, No. 3, pp. 411-416, September 2018.

[6] K. Bogos, "Analysis: Looking Back on the 2018 Kurdish Elections", Inistitute of Regional and International Studies (IRIS),AUIS, March 2019, Available at https://auis.edu.krd/iris/sites/default/files/Analysis_Looking\%20Back\%20on\%20the\%202018\%20Kurdish\%20Elec tions_March\%202019.pdf, Accessed on 27.5.2019.

[7] S. Ghimire and D. H. Selvaraj, "A Survey on Bitcoin Cryptocurrency and its Mining" 2018 26th International Conference on Systems Engineering (ICSEng), Sydney, Australia, 2018, pp. 1-6.

[8] T. Le Nguyen, "Blockchain in Healthcare: A New Technology Benefit for Both Patients and Doctors", 2018 Portland International Conference on Management of Engineering and Technology (PICMET), 2018.

[9] P. Zhang, J. White, D. Schmidt, G. Lenz and S. Rosenbloom, "FHIRChain: Applying Blockchain to Securely and Scalably Share Clinical Data", Computational and Structural Biotechnology Journal, vol. 16, pp. 267-278, 2018.

[10] H. Hellani, A. E. Samhat, M. Chamoun, H. E. Ghor and A. Serhrouchni, "On BlockChain Technology: Overview of Bitcoin and Future Insights," 2018 IEEE International Multidisciplinary Conference on Engineering Technology (IMCET), Beirut, 2018, pp. 1-8.

[11] D. Puthal, N. Malik, S. P. Mohanty, E. Kougianos and C. Yang, "The Blockchain as a Decentralized Security Framework [Future Directions]," in IEEE Consumer Electronics Magazine, vol. 7, no. 2, pp. 18-21, March 2018.

[12] Y. Chen, S. Chen and I. Lin, "Blockchain based smart contract for bidding system," 2018 IEEE International Conference on Applied System Invention (ICASI), Chiba, 2018, pp. 208-211.

[13] Azine Houria, Bencherif Mohamed Abdelkader, Guessoum Abderezzak, "A comparison between the secp256r1 and the koblitz secp256k1 bitcoin curves", Indonesian Journal of Electrical Engineering and Computer Science (IJEECS), Vol. 13, No. 3, pp. 910 918, March 2019.

[14] S. Wang, L. Ouyang, Y. Yuan, X. Ni, X. Han and F. Wang, "Blockchain-Enabled Smart Contracts: Architecture, Applications, and Future Trends," in IEEE Transactions on Systems, Man, and Cybernetics: Systems.

[15] P. Tasatanattakool and C. Techapanupreeda, "Blockchain: Challenges and applications," 2018 International Conference on Information Networking (ICOIN), Chiang Mai, 2018, pp. 473-475.

[16] S. Geiregat, "Cryptocurrencies are (smart) contracts", Computer Law \& Security Review, vol. 34, no. 5, pp. 1144-1149, 2018.

[17] Q. Xia, E. B. Sifah, K. Huang, R. Chen, X. Du and J. Gao, "Secure Payment Routing Protocol for Economic Systems Based on Blockchain," 2018 International Conference on Computing, Networking and Communications (ICNC), Maui, HI, 2018, pp. 177-181.

[18] Md Nazmus Saadat, Syed Abdul Halim, Husna Osman, Rasheed Mohammad Nassr and Megat F. Zuhairi, "Blockchain based crowdfunding systems", Indonesian Journal of Electrical Engineering and Computer Science (IJEECS), Vol. 15, No. 1, pp. 409-413, July 2019.

[19] A. Prashant and S.G. Santhosh, "A Relative Study on Bitcoin Minig", Imperial Journal of Interdisciplinary Research (IJIR), Vol. 3 issue 5 pp. 1757-1761, 2017.

[20] P. K. Kaushal, A. Bagga and R. Sobti, "Evolution of Bitcoin and security risk in Bitcoin wallets," 2017 International Conference on Computer, Communications and Electronics (Comptelix), Jaipur, 2017, pp. 172-177.

[21] R.M. Nelson, "International Approaches to Digital Currencies", Congressional Research Service, Library of Congress, Washington, D.C., 2018, Available at https://fas.org/sgp/crs/row/R45440.pdf, Accessed on 29.5.2019.

[22] N. Kshetri and J. Voas, "Blockchain-Enabled E-Voting" in IEEE Software, vol. 35, no. 4, pp. 95-99, July/August 2018.

[23] F. P. Hjálmarsson, G. K. Hreiðarsson, M. Hamdaqa and G. Hjálmtýsson, "Blockchain-Based E-Voting System" 2018 IEEE 11th International Conference on Cloud Computing (CLOUD), San Francisco, CA, 2018, pp. 983-986. 
[24] M. A. M.Sadeeq, S. R. M. Zeebaree, R. Qashi, S. H. Ahmed and K. Jacksi, "Internet of Things Security: A Survey," 2018 International Conference on Advanced Science and Engineering (ICOASE), Duhok, 2018, pp. 162-166.

\section{BIOGRAPHIES OF AUTHORS}

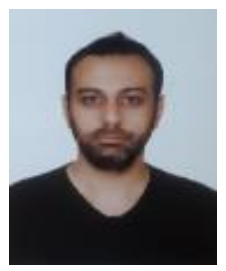

Hilmi Abdullah was born in Amedi, Duhok, Iraq. He received his M.Sc. degree in Software Engineering from Lappeenranta University of Technology, Finland, in 2011. His area of interest is Information Security, Blockchain and E-Governance, Email: Hilmi.Amedi@gmail.com

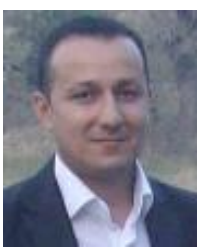

Ali Hikmat Ibrahim was born in Duhok, Iraq. He Received his M.Sc. degree in Information Technology, Dr. Baba Sahib University, India. His area of interest is Blockchain and Web Applications, Email: alihikmat31@gmail.com 